\title{
SPATIAL ASSOCIATIONS AND SPECIES COLLOCATION OF DOMINANT TREE SPECIES IN A NATURAL SPRUCE-FIR MIXED FOREST OF CHANGBAI MOUNTAINS IN NORTHEASTERN CHINA
}

\author{
ZHANG, M. ${ }^{1}-$ LIU, $\mathrm{Y}^{2}{ }^{2}-\mathrm{GUO}, \mathrm{W}^{3}{ }^{3}-\mathrm{KANG}, \mathrm{X}^{3^{*}}-\mathrm{ZHAO}, \mathrm{H}^{4}$ \\ ${ }^{1}$ College of Forestry, Shanxi Agriculture University, Shanxi 030801, P. R. China \\ ${ }^{2}$ College of Forestry, Inner Mongolia Agriculture University \\ Inner Mongolia 010019, P. R. China \\ ${ }^{3}$ Key Laboratory for Silviculture and Conservation Ministry of Education, Beijing Forestry \\ University, Beijing 100083, P.R. of China \\ ${ }^{4}$ Forest police college, Nanjing 210023, P.R. of China \\ ${ }^{*}$ Corresponding author \\ e-mail: zmt0411@163.com; phone: +86-018503444094; fax: +86-03546288329
}

(Received $5^{\text {th }}$ Nov 2018; accepted $4^{\text {th }}$ Feb 2019)

\begin{abstract}
In order to achieve of the spatial association and optimum collocation, a 1-ha natural spruce-fir mixed forest plot which was established on Changbai Mountains, PR China. Diameter at breast height, height, and the crown width of the standing free trees with $>1 \mathrm{~cm}$ DBH trees were measured, and species were identified. $O$-ring statistics and the nearest neighbor analysis were applied to test the spatial correlations and distribution of number of dominant species at different vertical layers. We found that: (1) according to the importance values, the top four species were Abies nephrolepis (Trautv.) Maxim., Picea koraiensis Nakai, Pinus. koraiensis Sieb. et Zucc. and Tilia. amurensis Rupr.; (2) most of species pairs have positive associations at small scales, while few are no relevance or have negative associations; (3) the number of juveniles and lower layer trees showed positive skewness under the upper layer trees and the maximum number for coniferous species was at a distance 4.5-6.5 m, while it was $6.5-8.5 \mathrm{~m}$ for broadleaved species. Our results provide a new insight into the development of reforestation technique in spruce-fir forests in the Changbai Mountains.
\end{abstract}

Keywords: inter-specific association, scale, O-ring statistics, nearest neighbor analysis

\section{Introduction}

Studying forest regeneration processes is essential in understanding forest diversity and dynamics, which follows a forest life cycle from germination to death (Darrigo et al., 2016). The information of forest regeneration, moreover, is fundamentally important because it reflects the stability of the structure and composition of overstory, and provides the prerequisites for the developing of ecological, social and economic benefits of forest continuously (Mostacedo et al., 2009; Lydersen et al., 2015). Forest management must change radically to maintain biodiversity and enough juveniles (Liu et al., 2015).

However, natural regeneration of seedlings and species cannot fulfill the requirements for the healthy growth of the forest due to landscape fragmentation, and the limitation of seed dispersal (Levesque et al., 2011; Holeksa et al., 2017). Artificial regeneration, therefore, can supplement the lack of woodland seedling individuals and the number of species (Wagner et al., 2010; Hejel et al., 2016). However, adaptive 
species must be chosen according to characteristics of alternative tree species (Gonzalez-Rodriguez et al., 2011).

A mount of studies, therefore, have been focused on the species niche and interspecific association of classical ecology with the objective to understand their optimal collocation of species effects on the forest ecosystem (Zhao et al., 2012; Su et al., 2015; Wright et al., 2016). In addition, more studies also have been focused on spatial structure, but only limited to a quantitative description of the forest spatial pattern (Li et al., 2014; Lydersen et al., 2015; Nguyen et al., 2016). Vertical spatial structure, however, is closely related to and affects the different ecological processes which include intra-specific and inter-specific competition, disturbance reaction, and environmental heterogeneity, regeneration mechanisms and understory development (Hao et al., 2007; Zhang et al., 2015). Ecology rules of spatial structure were rarely applied to forest management.

In this study, species spatial associations and distribution were analyzed with the distance at different vertical layers in a 1-ha spruce-fir mixed forest plot, to provide a scientific basis for the best collocation of different forest vertical layers of the mixed forest. We hoped to fulfill three objectives: (1) evaluate mechanisms of species coexistence though calculate species spatial associations between juveniles, lower and upper height class trees; (2) clarify the dependency relationship according to distributions of number of the species with the distance among different height layers; (3) indicate the distance or scale is an important factor among different tree height classes in the forest.

\section{Materials and methods}

\section{Study area}

Jin Gouling forest farm is our study area, which is located in Changbai Mountain in northeastern PR China $\left(43^{\circ} 22^{\prime} \mathrm{N}, 130^{\circ} 10^{\prime} \mathrm{E}\right)$ (Fig. 1). The annual precipitation is $500-600 \mathrm{~mm}$, with most of the rain falling in July. The altitude ranges from 300 to 1200 $\mathrm{m}$ and the slopes mostly vary between $5^{\circ}$ and $25^{\circ}$. A gray-brown podzolic soil is present on the low and intermediate mountains in the area and is derived from the parent basalt rock.

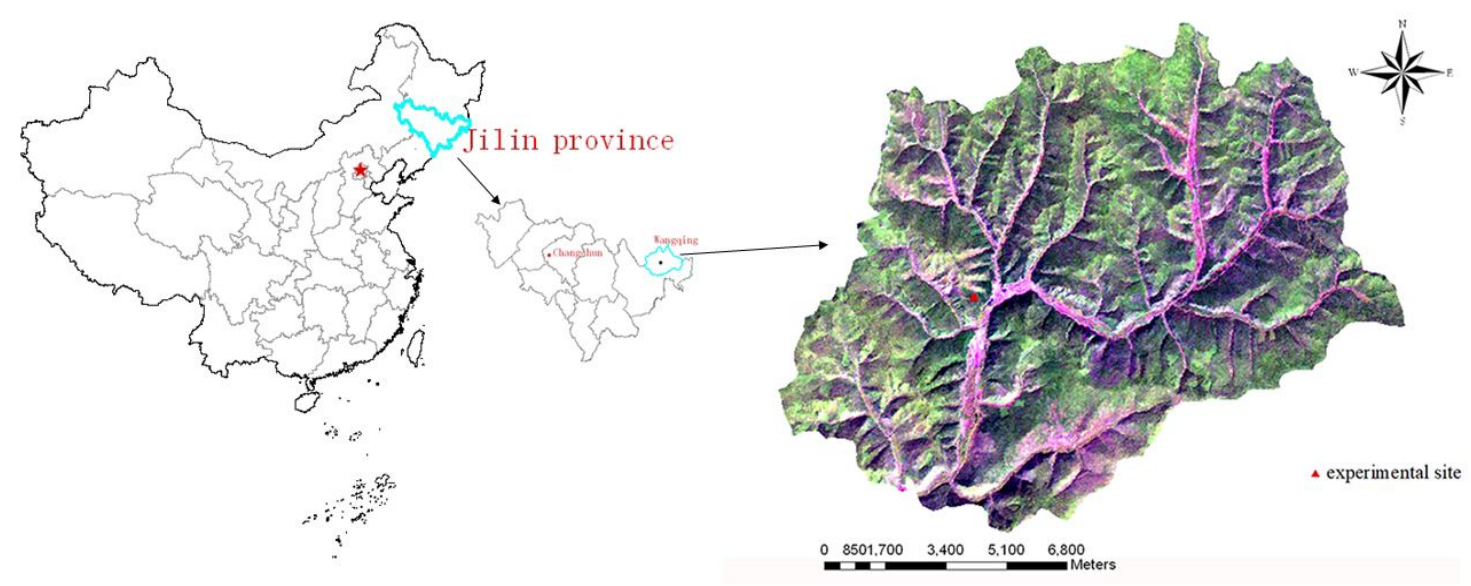

Figure 1. Location of study site within the Changbai Mountain in northeastern China 


\section{Plot establishment and data collection}

A $100 \mathrm{~m} \times 100 \mathrm{~m}$ plot was established in natural spruce-fir forest which suffered little distance because of it difficult accessibility. Twenty-five $20 \mathrm{~m} \times 20 \mathrm{~m}$ subplots were set in above-mentioned plot. All detailed information of stand description factors can be found in (Zhang, 2017).

\section{Data analysis}

\section{Forest spatial associations analysis}

$O$-ring statistic model was broadly employed to investigate structural forest processes (Wiegand and Moloney, 2004; Xu et al., 2009). Therefore, $O$-ring statistic model was used to explore the spatial associations of the dominate tree species. The $O$-ring statistics includes both univariate and bivariate statistics (Getzin et al., 2006). The $O$-ring statistic model $O_{12}(\mathrm{r})$ is calculated as:

$$
\hat{O}_{12}^{\mathrm{w}}(r)=\frac{\frac{1}{n_{1}} \sum_{i=1}^{n_{i}} \operatorname{Po} \text { int } s_{2}\left[R_{1},{ }_{i}^{w}(r)\right]}{\frac{1}{n_{1}} \sum_{i=1}^{n_{i}} \operatorname{Area}\left[R_{1},{ }_{i}{ }_{i}(r)\right]}
$$

where $n_{1}$ is the number of points of pattern 1 (the object 1 of univariate statistic), $R_{1},{ }_{i}{ }_{i}(\mathrm{r})$ means the ring with radius $r$ and ring width $w$ centered on the $i$ th point of pattern 1; Points $_{2}[\mathrm{X}]$ (Equation 2) calculate the number of points in regional $\mathrm{X}$ of pattern 2 (the object 2 of univariate statistic), Area[X] (Equation 4) means the area of the study regional $\mathrm{X}$.

$$
\begin{gathered}
\text { Po int } S_{2}\left[R_{1},{ }_{i}^{w}(r)\right]=\sum_{\text {allx }} \sum_{\text {ally }} S(x, y) P_{2}(x, y) I_{r}\left(x_{i}, y_{i}, x, y\right) \\
I_{\mathrm{r}}^{\mathrm{w}}\left(x_{i}, y_{i}, x, y\right)=\left\{\begin{array}{ccc}
1 & \text { if } & r-\frac{w}{2} \leq \sqrt{\left(x-x_{i}\right)^{2}+\left(y-y_{2}\right)^{2}} \leq r+\frac{w}{2} \\
0 & \text { otherwise }
\end{array}\right. \\
\text { Area }\left[R_{1},{ }_{i}^{w}(r)\right]=z^{2} \sum_{\text {all }} \sum_{\text {ally }} S(x, y) I_{r}\left(x_{i}, y_{i}, x, y\right)
\end{gathered}
$$

In these equations, $\left(x_{i}, y_{i}\right)$ is the coordinate of point $i$ in pattern 1 . When the coordinate of point $i$ is inside the study regional $\mathrm{X}, \mathrm{S}(x, y)=1$, otherwise, $S(x, \mathrm{y})=0$. $P_{2}(x, y)$ means the number of points in pattern 2, $I_{r}$ (Equation 3$)$ is a counter variable to define the circle with radius $r$ that is centered at the $i$ th point of pattern $1, z^{2}$ means the area of one cell. The univariate statistic $O_{i i}(r)$ is calculated by setting the pattern 1 equal to the pattern 2 .

\section{Nearest neighbor analysis}

Supposing that in a large enough forest stand, which existed plenty of juveniles of species A and adult tree of species $\mathrm{B}$, the number of juveniles of $\mathrm{A}$ is N. $D i$ is the 
distance from random juveniles of species $\mathrm{A}$ to the nearest adult tree of species $\mathrm{B}$, and the average distance between juveniles of species A and nearest adult trees of species B with the following formula:

$$
\bar{D}=\frac{1}{N} \sum_{i=1}^{N} D i
$$

where $\bar{D}$ is the mean distance from juvenile tree to mature individual, which is used to analyze the attachment relationship between juvenile and mature tree, $\sigma^{2}$ is the standard variance of $D i$.

Because of the limited area of the plot and number of individuals (juveniles and mature trees), it is difficult to calculate $D i$. The central limit theorem, therefore, was used here, which assumed that a juvenile and a nearest adult tree constitute a sample unit, when the sample number $\geq 50$, the average distance showed an approximately normal distribution (Rice, 2007).

$$
\frac{(\bar{d}-\bar{D})}{\sigma / \sqrt{n}} \cdot \frac{\text { approximately }}{n \geq 50} \sim N(0,1)
$$

and the formula can be obtained:

$$
p\left\{|\bar{d}-\bar{D}| \leq U_{\alpha} \cdot \frac{S}{\sqrt{n-1}}\right\}=1-\alpha
$$

where $U_{\alpha}$ is the expected value of the sample distance, $S$ is the variance of the standard sample distance, and the confidence interval is $\left[\bar{d}-U_{\alpha} \cdot \frac{S}{\sqrt{n-1}}, \bar{d}+U_{\alpha} \cdot \frac{S}{\sqrt{n-1}}\right]$. In addition, the distribution area was divided into juveniles of species A around the nearest adult tree of species B into several annular zones, and the center point was under the stem of adult tree. The ratio of number of juveniles of species A in each annular zone was counted. The distance, which distributed the maximal number of juveniles, was the optimal distance for replanting juveniles of species A under adult trees of species B (Zhao et al., 2012).

The spatial scale was set $0-20 \mathrm{~m}$, and in this case, 199 randomizations in Monte Carlo simulations were used to provide $95 \%$ confidence envelopes. In addition, the nearest neighbor was used to analyzed to test the distribution of number of dominant species with distance and identified the strength of the association among juvenile, lower height class and upper height class.

\section{Results}

\section{Stand structure}

Table 1 presents the descriptive statistics of species for the entire plot. According to important value, A. nephrolepis (Fir) ranked first and had the largest number (1638) and basal area $\left(12.90 \mathrm{~m}^{2} \mathrm{hm}^{-1}\right)$. P. jezoensis (Spruce) followed second with number (415), 
basal area $\left(6.18 \mathrm{~m}^{2} \mathrm{hm}^{-1}\right)$. Although $P$. koraiensis (Korean pine) had only 278 individuals, it ranked third in terms of important value. T. amurensis (Linden) had the largest DBH $(64 \mathrm{~cm})$ and its important value ranked fourth. It is basically the same data base that has been used in the study of (Zhang, 2017).

Table 1. Basic structural characteristics of tree species in a 1-ha uneven-aged natural spruce-fir forest plot in Changbai Mountain

\begin{tabular}{|c|c|c|c|c|c|c|}
\hline \multirow{2}{*}{ Species } & \multirow{2}{*}{ No. of trees } & \multicolumn{2}{|c|}{ DBH(cm) } & \multirow{2}{*}{ Standard deviation } & \multirow{2}{*}{$\begin{array}{c}\text { Basal area } \\
\left(\mathrm{m}^{2} \mathbf{h m}^{-1}\right)\end{array}$} & \multirow{2}{*}{ Important value } \\
\hline & & Max & Mean & & & \\
\hline $\begin{array}{l}\text { A. nephrolepis(Trautv.) } \\
\text { Maxim. (Fir) }\end{array}$ & 1638 & 45.2 & 9.9 & 9.79 & 12.90 & 69.67 \\
\hline $\begin{array}{c}\text { P. jezoensis Carr. } \\
\text { (Spruce) }\end{array}$ & 415 & 48.3 & 16.4 & 11.90 & 6.18 & 45.55 \\
\hline $\begin{array}{l}\text { P. koraiensis Sieb. et Zucc. } \\
\text { (Korean pine) }\end{array}$ & 278 & 55.5 & 13.9 & 13.22 & 4.37 & 40.46 \\
\hline $\begin{array}{c}\text { T. amurensis Rupr. } \\
\text { (Linden) }\end{array}$ & 342 & 64.0 & 6.7 & 7.88 & 2.15 & 39.15 \\
\hline $\begin{array}{l}\text { B. platyphylla Suk. } \\
\text { (White birch) }\end{array}$ & 33 & 30.4 & 17.7 & 5.73 & 1.35 & 10.85 \\
\hline $\begin{array}{l}\text { P. amurense Rupr. } \\
\text { (Yellow pineapple) }\end{array}$ & 4 & 11.8 & 15.2 & 3.47 & 0.07 & 4.20 \\
\hline $\begin{array}{l}\text { P. davidiana Dode } \\
\text { (Elm) }\end{array}$ & 3 & 30.4 & 19 & 9.95 & 0.09 & 4.19 \\
\hline
\end{tabular}

Intra- and interspecies spatial associations of dominant tree species were analyzed among different height classes (Table 2). All standing free trees were firstly divided the height into juvenile $(\mathrm{h}<5 \mathrm{~m})$, lower $(5 \mathrm{~m} \leq \mathrm{h}<10 \mathrm{~m})$, intermediate $(10 \mathrm{~m} \leq \mathrm{h}<15 \mathrm{~m})$ and upper $(\mathrm{h} \geq 15 \mathrm{~m})$ layer but most species were distributed at the juvenile trees and few individuals were found in the lower, intermediate and upper layer (Zhang, 2017).

Table 2. Basic quantity characteristics of four dominant tree species at four height classes

\begin{tabular}{c|c|c|c|c|c|c|c|c}
\hline \multirow{2}{*}{ Species } & \multicolumn{3}{|c|}{ Height (m) } & \multicolumn{2}{c|}{ Numbers of different height classes } & \multirow{2}{*}{ Total } \\
\cline { 2 - 7 } & Maximum & Minimum & Mean & J & L & M & U & \\
\hline A. nephrolepis & 21.9 & 0.3 & 4.58 & 1185 & 142 & 141 & 170 & 1638 \\
P. jezoensis & 24.4 & 0.6 & 5.7 & 265 & 101 & 20 & 69 & 415 \\
P. koraiensis & 21.0 & 0.3 & 5.17 & 175 & 50 & 31 & 22 & 278 \\
T. amurensis & 19.2 & 0.4 & 4.92 & 224 & 62 & 46 & 10 & 342 \\
\hline
\end{tabular}

$\mathrm{J}$ - juvenile height class $(\mathrm{h}<5 \mathrm{~m}), \mathrm{L}$-lower height class $(5 \mathrm{~m} \leq \mathrm{h}<10 \mathrm{~m})$, M-intermediate height class (10 $\mathrm{m} \leq \mathrm{h}<15 \mathrm{~m})$, U-upper height class $(\mathrm{h} \geq 15 \mathrm{~m})$

\section{Intra- and interspecies spatial association of dominant tree species between juvenile and upper layer trees (juvenile layer vs. upper layer trees)}

The spatial associations of the juvenile (J) and upper (U) layer trees varied with the scale that be examined (Fig. 2). The most dominant species of juvenile height class were positive correlations at small scales, and with scaling up, no relevance or even negative associations emerged. For instance, Tilia $(\mathrm{J})$ was positive associations to Tilia (U) and Pinus (U) both at scales 0-2 $\mathrm{m}$ and 8-9 m scales, Abies (U) and Picea (U) at 0-7 $\mathrm{m}$ and 0-6 m scales, repectively (Fig. 2a-2d). Similarly, Pinus (J) was positive associations to Tilia $(\mathrm{U})$ and Picea $(\mathrm{U})$ at $0-10 \mathrm{~m}$ and 0-7 $\mathrm{m}$ scales (Fig. 2e, 2h). Abies (J) 
and Picea (J), furthermore, were positive correlations to Tilia (U) at scales $\leq 7 \mathrm{~m}$ and $\leq 3 \mathrm{~m}$. Abies (J) was also positive associations to Abies (U) and Picea $(\mathrm{U})$ at scales $\leq 8 \mathrm{~m}$ and $\leq 10 \mathrm{~m}$ (Fig. $2 i, 2 k-2 m)$.

Three different associations were observed as follows: (1) Pinus (J) and Picea (J) were significant positive associations to Abies (U) at the majority of scales, so did Abies (J) to Pinus (U) and Picea (J) to Pinus (U) (Fig. 2g, 2j, 2n and 2o); (2) Pinus (J) exhibited no relevance and negative association to Pinus (U) at scales, and with the scales increased, positive association emerged (Fig. 2f); (3) Picea (J) was negative correlation to Picea (U) at 0-3 m and 9-10 m scales (Fig. $2 p$ ).
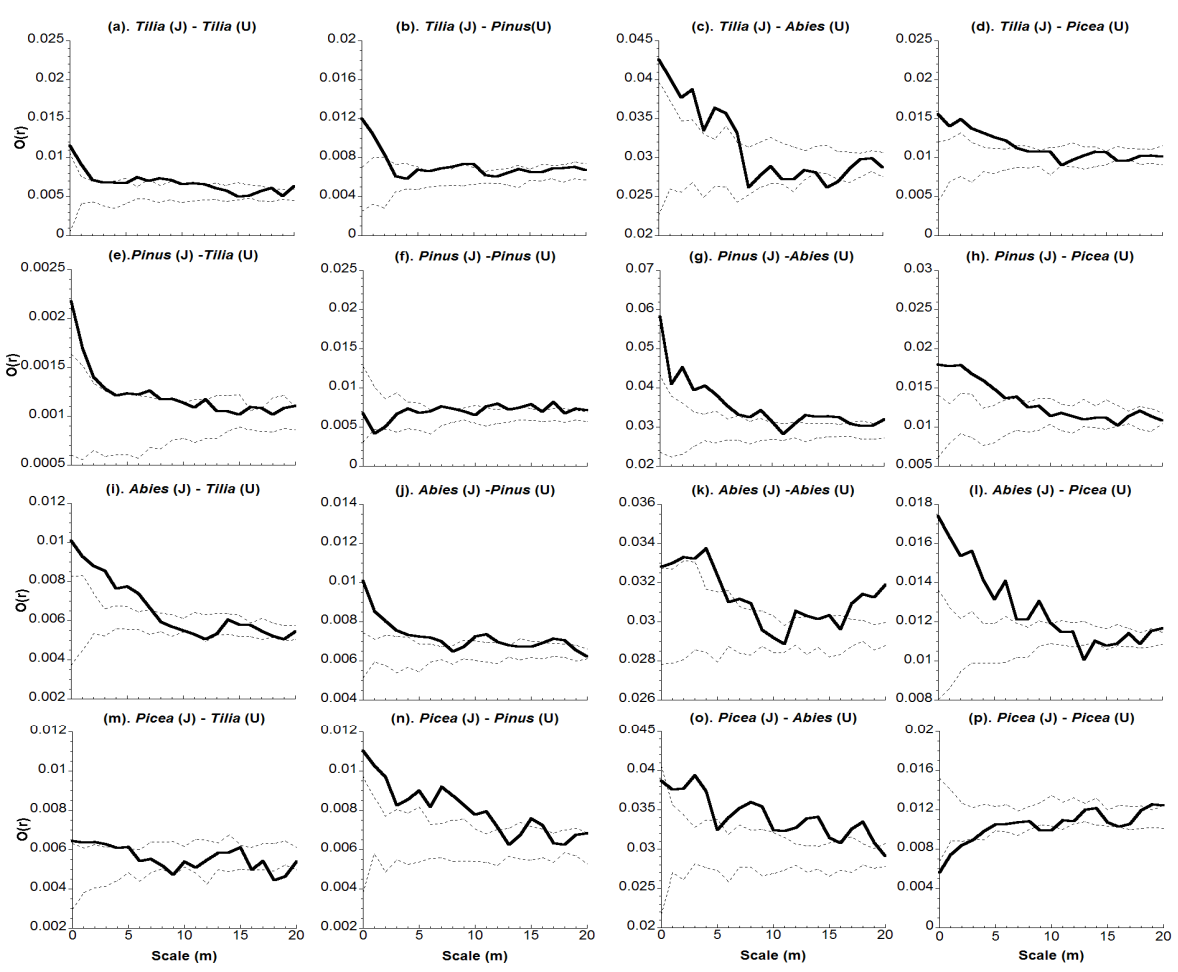

Figure 2. Spatial associations of juvenile height class to the upper height class. Black lines indicate ring statistics $O(r)$; dashed lines indicate upper and lower of the limit $95 \%$ confidence envelopes. Above the dashed lines indicate positive association between species pairs, below the dashed lines indicate positive association, and in the interval of dashed lines indicate independence between species pairs (similarly hereinafter). J: the juvenile height class, $U$ : the upper height class

\section{Intra- and interspecies spatial association of dominant tree species between lower and upper layer trees (lower vs. upper layer trees)}

The spatial associations of the lower (L) height class and upper (U) height class at different vertical layers (Fig. 3). Tilia (L) tended to show negative association to Tilia $(\mathrm{U})$ at 4-6 m and 10-11 m, and was positive correlation to Abies (U) at scales $\leq 1 \mathrm{~m}$, while no relevancies was observed to Pinus (U) and Abies (U) at the most scales. Pinus (L) was positively associated to Pinus (U) only at scales $\leq 3 \mathrm{~m}$ and with scaling up, more scales exhibited independence or even inhibition, (Fig. 3a-3d, 3f). It was found that Pinus (L) was significant positive association was showed at the most scales 


$$
-6219-
$$

$(\leq 15 \mathrm{~m}, \leq 15 \mathrm{~m}$ and $\leq 11 \mathrm{~m})$ to Tilia (U), Abies (U) and Picea (U) (Fig. 3e, 3g, 3h). Similarly, Abies (L) was positive correlation to all four species at scales $\leq 14 \mathrm{~m}, \leq 3 \mathrm{~m}$ and 7-10 m, $\leq 16 \mathrm{~m}$ and $\leq 8 \mathrm{~m}$ (Fig. 3i-3l). Picea (L) was positive correlation to Tilia (U), Pinus (U) and Abies (U) at scales $\leq 5 \mathrm{~m}, \leq 4 \mathrm{~m}$, and $\leq 6 \mathrm{~m}$, while negative association to Picea (U) at sacles $\leq 3 \mathrm{~m}$, respectively (Fig. $3 m-3 p$ ).
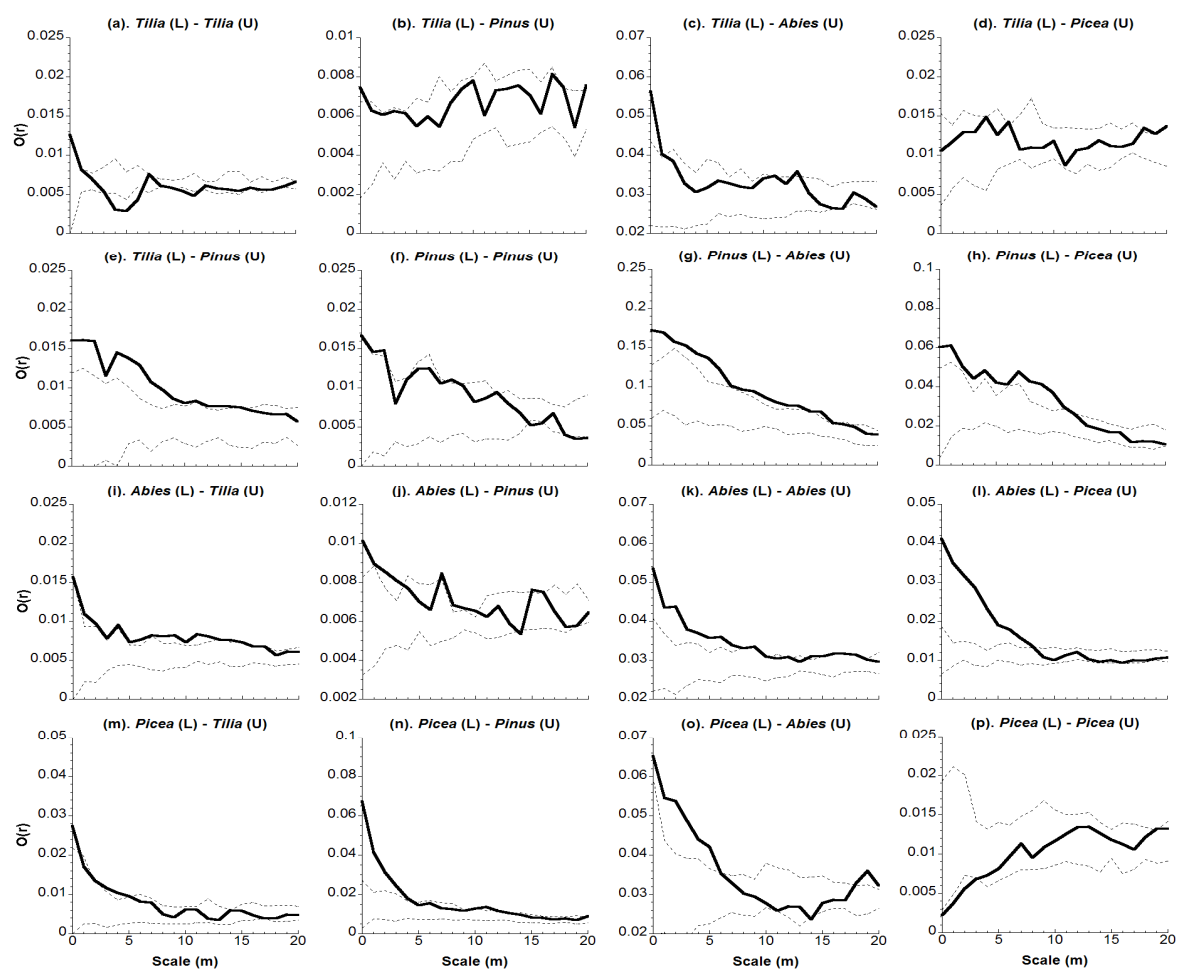

Figure 3. Spatial associations of lower height class to the upper height class. Black lines indicate ring statistics $O(r)$; dashed lines indicate upper and lower of the limit 95\% confidence envelopes. L: the lower height class, U: upper height class

\section{Distribution of the number of the dominant species with the distance at different height classes}

Four dominant species (J) were nearest to A. nephrolepis (U), while furthest to T. amurensis (U). In addition, the average distances among species (J) and species (U) were observed: (1) Tilia (U): Pinus (J) $<$ Tilia (J) $<$ Picea (J) $<$ Abies (J); (2) Pinus (U): Picea $(\mathrm{J})<$ Abies $(\mathrm{J})<$ Pinus $(\mathrm{J})<$ Tilia $(\mathrm{J}) ;(3)$ Abies $(\mathrm{U}):$ Picea $(\mathrm{J})<$ Pinus $(\mathrm{J})<$ Abies $(\mathrm{J})<$ Tilia $(\mathrm{J})$; (4) Picea (U): Tilia $(\mathrm{J})<$ Pinus $(\mathrm{J})<$ Abies $(\mathrm{J})<$ Picea $(\mathrm{J})$. The average distance between species (L) and species (U) was from $4.729 \mathrm{~m}$ to $8.877 \mathrm{~m}$. The average distance to species (U) specific to species (L) were showed: (1) Tilia (U): Tilia (L) $<$ Pinus (L) $<$ Abies (L) $<$ Picea (L); (2) Pinus (U): Pinus (L) $<$ Abies (L) $<$ Tilia (L) $<$ Picea (L); (3) Abies (U): Picea (L) $<$ Abies (L) $<$ Pinus (L) $<$ Tilia (L); (4) Picea (U): Abies (L) $<$ Pinus (L) $<$ Tilia (L) $<$ Picea (L).

The results of distribution of the number between juvenile were shown that lower and upper height class trees (Fig. 4 and Fig. 5). All skewness values were greater than zero. Positive skewness, therefore, was observed (Tab.3). The number of species (J) and species (L) under the upper layer trees was first gradually increased with the distance, 


$$
-6220-
$$

and then decreased beyond a certain critical point. It was found that the distributions of the greatest number of species (J) and species (L) from $4.5 \mathrm{~m}$ to $10.5 \mathrm{~m}$ scales. For instance, four species $(\mathrm{J})$ were mainly distributed in the range of 4.5 to $6.5 \mathrm{~m}$ scales under Picea (U), 4.5 to $8.5 \mathrm{~m}$ under Pinus (U) and Abies (U), while 6.5 to $10.5 \mathrm{~m}$ under Tilia (U) (Fig. 4). Furthermore, all the species (L) were distributed in the range of 4.5 to $8.5 \mathrm{~m}$ under Tilia $(\mathrm{U})$, Abies $(\mathrm{U})$ and Picea $(\mathrm{U})$, while 4.5 to $10.5 \mathrm{~m}$ scales under Pinus (U) (Fig. 5).
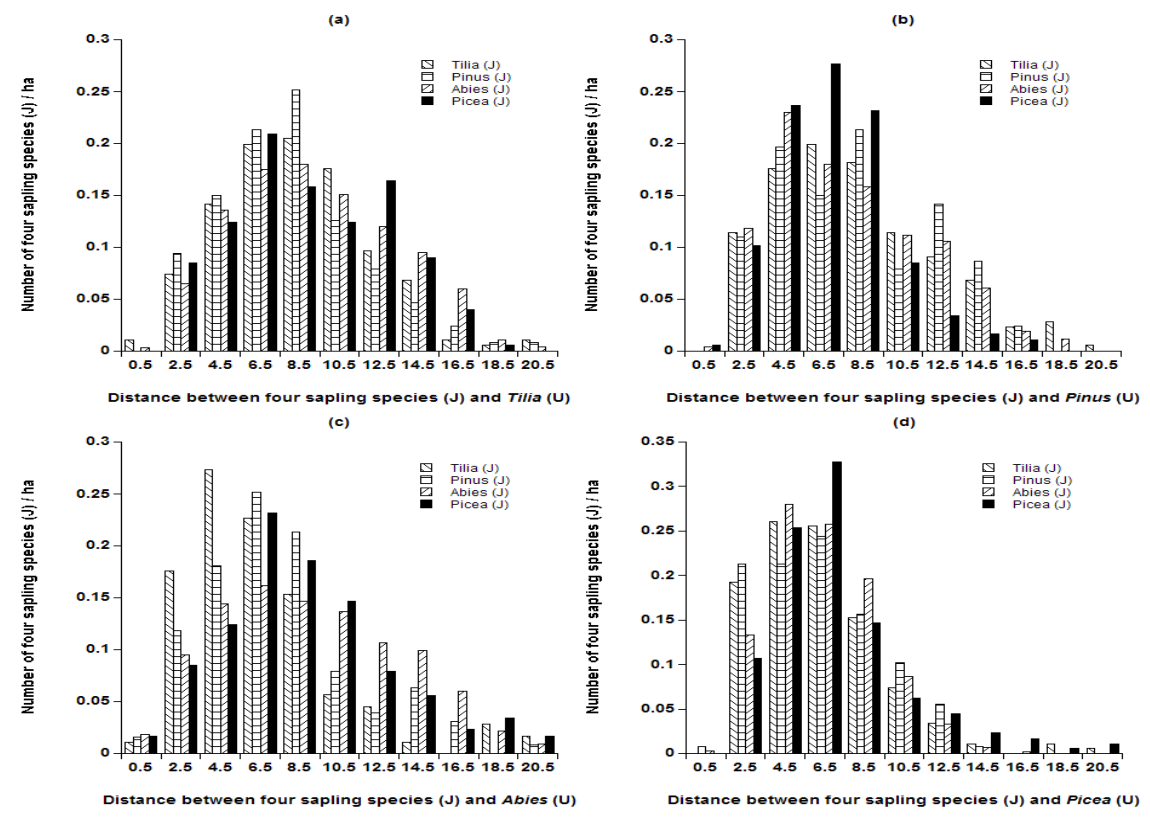

Figure 4. Distribution between juvenile (J) and upper (U) height classes of four dominant species with the distance
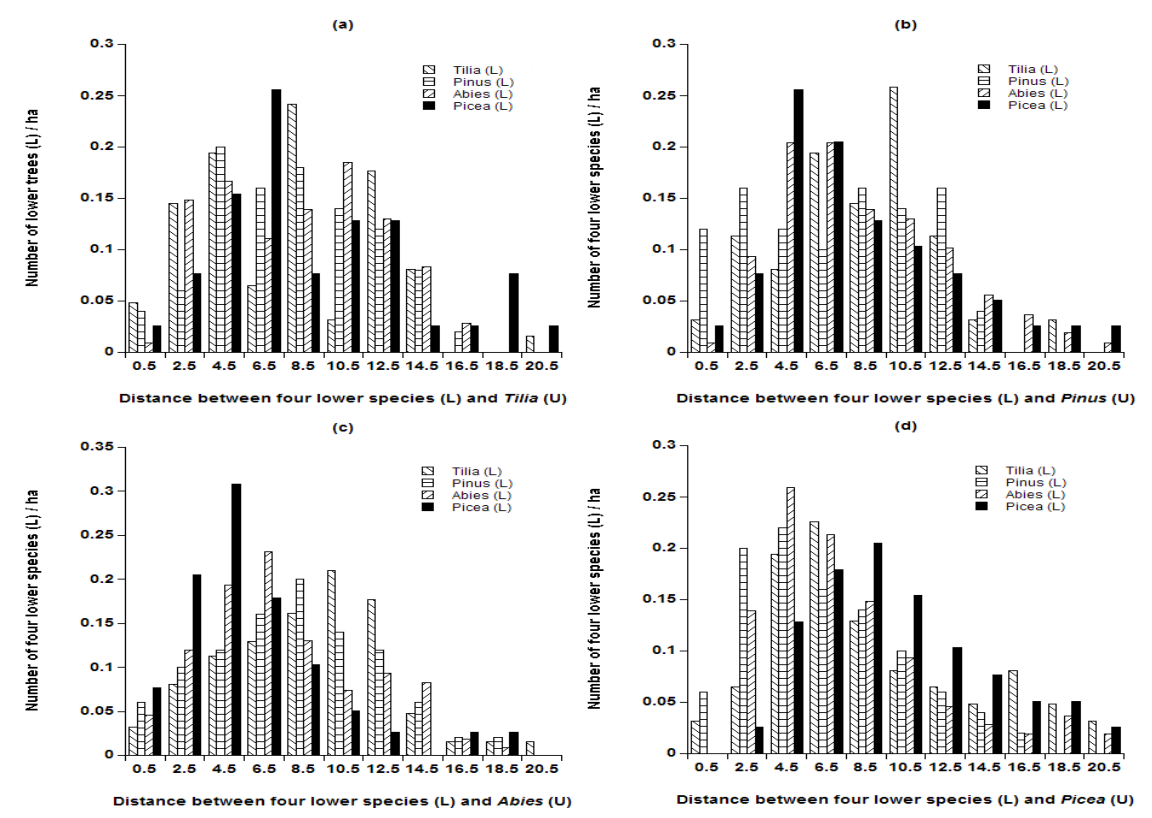

Figure 5. Distribution between lower $(L)$ and upper $(U)$ height classes of four dominant species with the distance 


\section{Discussion}

The study site is an uneven-aged spruce-fir mixed forest where has abundant tree species and complicated stand structure. According to importance value index, the dominant species are ranked to A. nephrolepis, $P$. jezoensis, $P$. koraiensis and T. amurensis. The same result has been reported in previous study (Gong, 2009), which according to analysis of forest dynamic (succession and restoration), the dominant trees were above mentioned species, and they will not change much with the development process.

Forest spatial association is closely related to scales (Navarro-Cerrillo et al., 2013; Zhang et al., 2015). Generally, juvenile and lower height classes tended to be positive association at smaller scales, with scales increased, it was changed by no relevance or even negative association (Fig. 2 and Fig. 3). The same results have been reported in some researches (Hao et al., 2007; Zhang et al., 2009). Some researchers thought that habitat heterogeneity and seeds dispersal ability with mother tree which resulted in positive association (Hubbell et al., 1999; Lin et al., 2011; Basnou et al., 2016). In addition, effect of intra specific competition was also important factor (Petritan et al., 2014).

Tilia $(\mathrm{J})$ and Abies $(\mathrm{J})$ are positive associations around their mother upper trees at small scales, while with scales increase, no relevance or negative association emerge (Fig. $2 a$ and $2 k$ ). Limited seed dispersal ability and their shade tolerant characteristics ensure them grow well under the canopy of parent trees in weak light. Although the coexistence may lead to competition and increase mortality, more juveniles can grow well under the canopy of the upper layer trees. Since then, with juveniles grow continually, few nutrients can be supplied for juveniles, more deaths appear. Distance among juveniles increase, therefore, the degree of aggregation decline (Kobe and Vriesendorp, 2011). In addition, positive associations between other three juvenile species and Tilia (U) explain coniferous species which can keep exuberant vitality under Tilia canopies (Fig. 2e, $2 i$ and $2 \mathrm{~m}$ ), which supported the previous researches (Zhang et al., 2007; Chen et al., 2009). Except above-mentioned reasons, positive association of three juvenile and lower layer species to other upper species may suggest two reasons: (1) they have broad niches; (2) complex structure of branches of upper layer trees blocks the seeds dispersal, which leads to wind propagation insignificant. The same results are argued in previous researches (Li et al., 2007; Sebkova et al., 2012).

Strongly positive associations at the most scales were observed between species (J), $(\mathrm{L})$ and species (U) suggest that the canopy of upper layer trees may provide suitable recruitment conditions for the understory. For instance, Pinus (J), Picea (J) and Abies (U), Abies (J), Picea (J) and Pinus (U) (Fig. 2g, 2j, 2o and 2n), Pinus (L) and Species (U) except Pinus (U) (Fig. 3e, 3g, and 3h), Abies (L) and Tilia (U), Abies (L) and Abies (U) (Fig. 3i and 3k), etc. Zhao et al. (2012) argued that these four species were the dominant species in this community, and trees of species pairs needed similar growth environment. Although their niches overlapped with each other, they can coexistence though competition of mutually promotive.

Negative associations for a few species (J) and (L) to their upper layer trees at small scales were observed. Take Pinus, Picea and Tilia for example, the negative association among Pinus might be attributable to human interference. Most pinecones were harvested, because of great economic value and this led to the lack of understory trees (Tao et al., 1995; Liu et al., 2004). The reason of exclusion among Picea different height class may be unsuited micro environmental conditions for their survival, 
establishment, and growth of juveniles and lower trees. The same result reported in previous research (Gilbert, 2002). Juvenile of Tilia has shade tolerant characteristic, with tree height increases, however, the growth of Tilia needs more light, which cannot develop under the overstory (Zhang et al., 2007).

The average distance of different tree height layers (Tab.3) are showed that Pinus (J) and Tilia (J) are most likely to growth under the canopy of Picea (U) and Tilia (U); similarly, Picea (J) establish under the canopy of Pinus (U) and Abies (U) easily, but difficultly under Picea (U). These results are consistent with the spatial association analysis. Nevertheless, the analyses of mean distance are observed that Tilia (L), Pinus(L) are most favored growth under their parent trees, which is inconsistent with the result of the spatial association. The difference between two analytical of two methods may be led to different results.

The distributions of the number among different tree height class were observed that the number of species $(\mathrm{J})$ and $(\mathrm{L})$ increased with distance until a maximum value reached, and then decreased with distance gradually (Fig. 3 and Fig. 4). The distribution of maximum number mainly kept in a range, rather than in their immediate vicinity, the same result was reported in previous research (Schupp and Jordano, 2011). In addition, maximum number of juveniles of four dominant species was distributed from $4.5 \mathrm{~m}$ to $10.5 \mathrm{~m}$, and this finding can be illustrated in Janzen-Connell theory in a certain extent, which high mortality is likely to occur near the mature trees (Matthesius et al., 2011; Steinitz et al., 2011). Meanwhile, the distribution of number of juveniles were influenced significantly by the crown widths, because of the canopy inhibited the growth of shrubs and herbs, more understory trees, therefore, can grow well in upper height trees (Pretzsch and Dieler, 2012). The distribution of maximum number for coniferous trees (Pinus, Abies and Picea) was at distance 4.5-6.5 m, while 6.5-8.5 m for broadleaved tree (Tilia) (Fig. 3 and Fig. 4). (Zhao et al., 2012) considered the length of coniferous tree is longer than broadleaved tree and the larger the crown width, therefore, the longer optimum distance occurred.

\section{Conclusions}

Our major aim was to understand the spatial reciprocity among different tree-height classes of dominant species in a mixed forest. The conclusions were shown that: (1) vertical structure plays an important role in population regeneration and community dynamics; (2) relative to the natural regeneration, artificial regeneration by enrichment planting is an expensive method, but has an obvious advantage in terms of the flexibility of either species combinations or spatial arrangements; (3) distance or scale is an important factor for distribution of trees. In different distance or scale, result of distribution of trees may be different. To obtain the optimum result, suitable distance or scale should be chosen according to situation of research in the plot. In addition, environmental factors, natural or human interference factors and the long-term monitoring data should also be considered and examined.

Acknowledgements. This study was supported by the project of applied basic research of Shanxi Province (Grant No. 201801D221302) and the planning subject of science and technology innovation of Shanxi agricultural university in China (Grant No. 2015YJ17). The author also thanked the editor and all anonymous reviewers for their constructive suggestions. 


\section{REFERENCES}

[1] Basnou, C., Vicente, P., Espelta, J. M., Pino, J. (2016): Of niche differentiation, dispersal ability and historical legacies: what drives woody community assembly in recent Mediterranean forests? - Oikos 125: 107-116.

[2] Chen, L., Zhao, X. H., Zhang, Y. (2009): Spatial distribution patterns and associations of Pinus koraiensis and Tilia amurensis in Tilia-Korean pine forest on the north slope of Changbai Mountain, northeastern China. - Journal of Beijing Forestry University 31: 6-10. (in Chinese).

[3] Darrigo, M. R., Venticinque, E. M., dos Santos, F. A. M. (2016): Effects of reduced impact logging on the forest regeneration in the central Amazonia. - Forest Ecology and Managemen 360: 52-59.

[4] Getzin, S., Dean, C., He, F. L., Trofymow, J. A., Wiegand, K., Wiegand, T. (2006): Spatial patterns and competition of tree species in a Douglas-fir chronosequence on Vancouver Island. - Ecography 29: 671-682.

[5] Gilbert, G. S. (2002): Evolutionary ecology of plant diseases in natural ecosystems. Annual Review of Phytopathology 40: 13-43.

[6] Gong, Z. W. (2009): Dynamics of Forest Succession and Restoration Strategies for Degraded Spruce-fir Forest in Changbai Mountain. - [PhD dissertation] Beijing, China: Beijing Forestry University (in Chinese).

[7] Gonzalez-Rodriguez, V., Navarro-Cerrillo, R. M., Villar, R. (2011): Artificial regeneration with Quercus ilex L. and Quercus suber L. by direct seeding and planting in southern Spain. - Annals of Forest Science 68: 637-646.

[8] Hao, Z. Q., Zhang, J., Song, B., Ye, J., Li, B. (2007): Vertical structure and spatial associations of dominant tree species in an old-growth temperate forest. - Forest Ecology and Management 252: 1-11.

[9] Hejel, P., Katona, K., Békési, S., Szemethy, L. (2016): Effects of natural and artificial beech regeneration methods on food diversity and browsing intensity in the Inner Western Carpathians. - Austrian Journal of Forest Science 133: 139-156.

[10] Holeksa, J., Jaloviar, P., Kucbel, S., Saniga, M., Svoboda, M., Szewczyk, J., Szwagrzyk, J., Zielonka, T., Zywiec, M. (2017): Models of disturbance driven dynamics in the West Carpathian spruce forests. - Forest Ecology and Managemen 388: 79-89.

[11] Hubbell, S. P., Foster, R. B., O'Brien, S. T., Harms, K. E., Condit, R., Wechsler, B., Wright, S. J., Loo de Lao, S. (1999): Light-Gap disturbances, recruitment limitation, and tree diversity in a neotropical forest. - Science 283: 554-557.

[12] Kobe, R. K., Vriesendorp, C. F. (2011): Conspecific density dependence in seedlings varies with species shade tolerance in a wet tropical forest. - Ecology Letters 14: 503-510.

[13] Levesque, M., McLaren, K. P., McDonald, M. A. (2011): Recovery and dynamics of a primary tropical dry forest in Jamaica, 10 years after human disturbance. - Forest Ecology and Management 262: 817-826.

[14] Li, Z., Xie, Z. Q., Li, Q. M., Zhao, C. M., Li, C. L. (2007): Spatial and temporal pattern of seed rain of Abies fargesii in Shennongjia Nature Reserve, Hubei. - Biodiversity Science 15(5): 500-509. (in Chinese).

[15] Li, Y. F., Hui, G. Y., Zhao, Z. H., Hu, Y., Ye, S. (2014): Spatial structural characteristics of three hardwood species in Korean pine broad-leaved forest-Validating the bivariate distribution of structural parameters from the point of tree population. - Forest Ecology and Management 314: 17-25.

[16] Lin, Y. C., Chang, L. W., Yang, K. C., Wang, H. H., Sun, I. F. (2011): Point patterns of tree distribution determined by habitat heterogeneity and dispersal limitation. - Oecologia 165: 175-184.

[17] Liu, Z. G., Ji, L. Z., Hao, Z. Q., Zhu, J., Kang, H. (2004): Effect of cone-picking on natural regeneration of Korean pine in Changbai Mountain Nature Reserve. - Chinese Journal of Applied Ecology 15: 958-962. (in Chinese). 
[18] Liu, X. Z., Lu, Y. C., Xie, Y. S., Xue, Y. (2015): The positive interaction between two nonindigenous species, Casuarina (Casuarina equisetifolia) and Acacia (Acacia mangium), in the tropical coastal zone of south China: stand dynamics and soil nutrients. - Tropical Conservation Science 8: 598-609.

[19] Lydersen, J. M., Collins, B. M., Knapp, E. E., Roller, G. B., Stephens, S. (2015): Relating fuel loads to overstorey structure and composition in a fire-excluded Sierra Nevada mixed conifer forest. - International Journal of Wildland Fire 24: 484-494.

[20] Matthesius, A., Chapman, H., Kelly, D. (2011): Testing for Janzen-Connell Effects in a West African Montane Forest. - Biotropica 43: 77-83.

[21] Mostacedo, B., Putz, F. E., Fredericksen, T. S., Villca, A., Palacios, T. (2009): Contributions of root and stump sprouts to natural regeneration of a logged tropical dry forest in Bolivia. - Forest Ecology and Management 258: 978-985.

[22] Navarro-Cerrillo, R. M., Manzanedo, R. D., Bohorque, J., Sánchez, R., Sánchez, J., de Miguel, S., Solano, D., Qarro, M., Griffith, D., Palacios, G. (2013): Structure and spatio-temporal dynamics of cedar forests along a management gradient in the Middle Atlas, Morocco. - Forest Ecology and Management 289: 341-353.

[23] Nguyen, H. H., Uria-Diez, J., Wiegand, K. (2016): Spatial distribution and association patterns in a tropical evergreen broad-leaved forest of north-central Vietnam. - Journal of Vegetation Science 27: 318-327.

[24] Petritan, I. C., Marzano, R., Petritan, A. M., Lingua, E. (2014): Overstory succession in a mixed Quercus petraea-Fagus sylvatica old growth forest revealed through the spatial pattern of competition and mortality. - Forest Ecology and Management 326: 9-17.

[25] Pretzsch, H., Dieler, J. (2012): Evidence of variant intra- and interspecific scaling of tree crown structure and relevance for allometric theory. - Oecologia 169: 637-649.

[26] Rice, J. A. (2007): Mathematical statistics and data analysis. - China machine press, Beijing.

[27] Schupp, E. W., Jordano, P. (2011): The full path of Janzen-Connell effects: genetic tracking of seeds to adult plant recruitment. - Molecular Ecology 20: 3953-3955.

[28] Sebkova, B., Samonil, P., Valtera, M., Adam, D., Janik, D. (2012): Interaction between tree species populations and windthrow dynamics in natural beech-dominated forest, Czech Republic. - Forest Ecology and Management 280: 9-19.

[29] Steinitz, O., Troupin, D., Vendramin, G. G., Nathan, R. (2011): Genetic evidence for a Janzen-Connell recruitment pattern in reproductive offspring of Pinus halepensis trees. Molecular Ecology 20: 4152-4164.

[30] Su, S. J., Liu, J. F., He, Z. S., Zheng, S. Q., Hong, W., Xu, D. W. (2015): Ecological species groups and interspecific association of dominant tree species in Daiyun Mountain National Nature Reserve. - Journal of Mountain Science 12(3): 637-646.

[31] Tao, D. L., Zhao, D. C., Zhao, S. D., Hao, Z. Q. (1995): Dependence of natural regeneration of Korean Pine on animals-An out closure experiment. - Chinese Biodiversity 3: 131-133. (in Chinese).

[32] Wagner, S., Collet, C., Madsen, P., Nakashizura, T., Nyland, R. D., Sagheb-Talebi, K. (2010): Beech regeneration research: From ecological to silvicultural aspects. - Forest Ecology and Management 259: 2172-2182.

[33] Wiegand, T., Moloney, K. A. (2004): Rings, circles, and null-models for point pattern analysis in ecology. - Oikos 104: 209-229.

[34] Wright, S. J., Calderon, O., Hernandez, A., Detto, M., Jansen, P. A. (2016): Interspecific associations in seed arrival and seedling recruitment in a Neotropical forest. - Ecology 97: 2780-2790.

[35] Xu, X. M., Harwood, T. D., Pautasso, M., Jeger, M. J. (2009): Spatio-temporal analysis of an invasive plant pathogen (Phytophthora ramorum) in England and Wales. - Ecography 32: 504-516.

[36] Zhang, J., Hao, Z. Q., Song, B., Ye, J., Li, B. H., Yao, X. L. (2007): Spatial distribution patterns and associations of Pinus koraiensis and Tilia amurensis in broad-leaved Korean 


$$
-6225-
$$

pine mixed forest in Changbai Mountains. - Chinese Journal of Applied Ecology 18: 1681-1687. (in Chinese).

[37] Zhang, J., Hao, Z. Q., Sun, I. F., Song, B., Ye, J., Li, B., Wang, X. (2009): Density dependence on tree survival in an old-growth temperate forest in northeastern China. Annals of Forest Science 66(204): 1-9.

[38] Zhang, M. T., Kang, X. G., Meng, J. H., Zhang, L. X. (2015): Distribution patterns and associations of dominant tree species in a mixed coniferous-broadleaf forest in the Changbai Mountains. - Journal of Mountain Science 12: 659-670.

[39] Zhang, M. T. (2017): Spatial Assocaition and Optimum Adjacent Distribution of Trees In a Mixed Coniferous-Broadleaf Forest In Northeastern China. - Applied Ecology and Environmental Research 15: 1551-1564.

[40] Zhao, H. Y., Kang, X. G., Guo, Z. Q., Yang, H., Xu, M. (2012): Species Interactions in Spruce-Fir Mixed Stands and Implications for Enrichment Planting in the Changbai Mountains, China. - Mountain Research and Development 32: 187-196. 